\title{
Magnitude of menstrual problems among young females of medical and paramedical college
}

\author{
Deepshikha Jaiswal, Rahul Kumar*
}

Department of Obstetrics and Gynecology, Kalra Hospital Kirti Nagar New Delhi, India

Received: 15 March 2021

Accepted: 13 April 2021

*Correspondence:

Dr. Rahul Kumar,

E-mail: rahuld16050@gmail.com

Copyright: (C) the author(s), publisher and licensee Medip Academy. This is an open-access article distributed under the terms of the Creative Commons Attribution Non-Commercial License, which permits unrestricted non-commercial use, distribution, and reproduction in any medium, provided the original work is properly cited.

\begin{abstract}
Background: Menstruation is described as the exclusive sign of femininity. The age of menarche is determined by general health, genetic, socio-economic, nutritional factors, geographic location, exposure to light and psychological state. Objective of current study was to determine the magnitude of menstrual problem among young females of age group17-25 years of medical and paramedical college.

Methods: The present study has been conducted on 300 young female students studying in the department of obstetrics and gynaecology in collaboration with paramedical and nursing college, RIMS and R. Saifai, Etawah over a period of 18 months January 2015 to July 2016, with an objective to determine the magnitude of menstrual problem among on young female students of age group 17-25 years.

Results: Mean age of the study population was 21.98 years. The mean age of menarche was found to be 13.50 years with standard deviationof 1.315. This was also in accordance with the results of previous studies. The average duration of menstrual blood loss was found to be 4.28 days with standard deviation of 1.092 . The average duration of normal blood flow for reproductive age group as estimated is 2-5 days. The mean of menstrual cycle length came out to be 29.79 days with a standard deviation of 4.87 . The average amount of blood loss during each menstrual cycle was found to be $65.39 \mathrm{ml}$ with a standard deviation of 11.81 .

Conclusions: It was concluded that the mean age of menarche was found to be 13.50 years with standard deviation of 1.315. The average duration of normal blood flow for reproductive age group as estimated is 2-5 days.
\end{abstract}

Keywords: Magnitude, Menstrual problems, Young females, Medical and paramedical college

\section{INTRODUCTION}

The mean age of menarche is typically between 12 and 13 years. $^{1}$ The initial cycles after menarche are often irregular with a particularly greater interval between first and second cycle. The early menstrual cycles are thought to be anovulatory. ${ }^{2}$

Most women bleed for 2 to 7 days during their first menses $^{3}$. Most normal cycles range from 21 to 45 days, despite variability even in the first gynaecologic year, although short cycles of fewer than 20 days and long cycles of more than 35 days mayoccur. By the third year after menarche, $60 \%$ to $80 \%$ of menstrual cycles are 21 to 34 days long, as is typical of adults. ${ }^{3}$ Menstruation is a physical manifestation of complex endocrine axis .Thus, the regularity and frequency of the menstrual cycle is sensitive to endocrine disturbances that may otherwise remain sub clinical. ${ }^{4}$

Many girls or women may be unfamiliar with what constitutes normal or abnormal menstrual pattern. Additionally, girls often are reluctant to discuss this very private topic with parents. Some girls seek medical advice for cycle variations that may be within the normal range. Others are unaware that their bleeding patterns are 
abnormal, with potential health consequences. ${ }^{5}$ Factors that often play a role in the regularity and flow of a woman's menstrual cycle include hormonal changes, genetics, serious medical conditions and body mass index. The aim therefore is tokeep BMI within the normal range to promote regular and healthy menstrual cycles. ${ }^{6}$ Menstrual cycle irregularities and anovulation have been found to occur with increased frequency in women who deviate considerably from normal weight.

A number of studies have shown that higher obesity grades were associated with higher probabilities of irregular pattern of menstrual cycles. ${ }^{7}$ In many instances, young patients seek medical attention for menstrual irregularities, which actually fall within the normal range. Menstrual problems are generally perceived as only minor health concern and thus irrelevant to the public health agenda particularly for women in developing countries who may face life threatening conditions.

Menstrual cycle is a normal physiological process that is characterized by periodic and cyclic shedding of progestational endometrium accompanied by loss of blood which adds a powerful tool to the assessment of normal development and the exclusion of pathological conditions in adolescent and young girls. ${ }^{8}$ Some variety of menstrual dysfunction occurs in adolescent girls which may affect normal life of adolescent and young adult women. Physical, Mental, Social, Psychological and Reproductive problems are often associated with menstrual irregularities and menstrual problems. Due to change in life style, habits, diet, the prevalence of obesity has increased in the developed world which has resulted in decreased age at menarche. ${ }^{9}$

Though menstruation is a regular phenomenon in females, almost all of them face some or the other kinds of problem, during these time. Menstrual conditions are many that may require physician's attention or any other healthcare professionals' attention. The most common menstrual disorders are pre-menstrual syndrome, dysmenorrhoea, amenorrhoea, menstrual cycle length disorders as oligomenorrhoea and polymenorrhoea etc. ${ }^{10}$ These teenage menstrual problems are diverse in aetiology and if detected early they can be remedied. The young girl is a very shy person and often hesitates to seek help regarding her problems. Current study is planned to determine the magnitude of menstrual problem among young females ofmedical and paramedical college.

\section{METHODS}

The present study has been conducted on 300 young female students studying in the department of obstetrics and gynaecology in collaboration with paramedical and nursing college, Uttar Pradesh. RIMS and R. Saifai, Etawah over a period of 18 months January 2015 to July 2016, with an objective to determine the magnitude of menstrual problem among on young female students of age group 17-25 years.

\section{Sample size}

Within the $5 \%$ of its actual parameters the estimated sample size with $95 \%$ of confidence interval was approximately 300 .

\section{Inclusion criteria}

Inclusion criteria for current study were; young females in the age group of 17-25 years, unmarried girls and those who were willing to participate in the study.

\section{Exclusion criteria}

Exclusion criteria for current study were; the young females who were not willing to participate, those who were on treatment for menstrual problems, married females, those having primary amenorrhoea and those who have undergone pelvic surgery.

\section{Procedure}

Structured questionnaire was used to determine the occurrence of menstrual problems among young females. Permission was taken from the selected colleges. Consent was taken from the selected students and a structured questionnaire was given to identify menstrual problems. The questionnaire consisted detailed history of the cases like present age, daily calorie intake, socioeconomic status, daily intake of junk foods, their detailed history of menstrual cycle pattern, age of menarche (on recall basis), dysmenorrhoea, passage of clots, hypomenorrhoea, menorrhagia, premenstrual symptoms if any, medical and drug history family history, etc. Detailed history of menstrual cycle was evaluated to find out the menstrual abnormality among these theoretically described ones. Short cycles (polymenorrhoea) with cycle length less than 21 days, long cycles (oligomenorrhoea) with cycle length more than 35 days, normal cycles from 21 to 35 days, normal duration 2 to 7 days were taken. Amount of bleeding was assessed by number of pads used/day and presence and absence of clots. A thorough general examination with special attention to pallor, icterus, thyroid enlargement, per abdominal examination was done.

\section{Statistical analysis}

The collected data was analysed using descriptive (mean, median and standard deviation) and inferential statistics and the results are presented by using diagrams, graphs and tables. The relationship between the parameters i.e. BMI and menstrual abnormality was tested using the Chi square test and independent sample t-test, $p>0.05$ was considered as non significant, $\mathrm{p}<0.05$ as significant and $\mathrm{p}<0.01$ as highly significant. 


\section{RESULTS}

The maximum number of cases was in the age group 21 to 23 years i.e. 160 cases $(53.33 \%)$. 77 cases $(25.66 \%)$ presented in the age group of 17 to 20 years. Least number of cases was found in 24 to 25 year group i. e. $21 \%$. The mean age of study sample was found to be 21.98 years with a standard deviation of 2.0. There are maximum cases in 22 and 23 years of age i.e. 55 each. 40 cases belonged to 20 years and 25 years each. Minimum numbers of cases were present in the age 24 years. None of cases were present in 17 and 18 years (Table 1).

Table 1: Distribution of cases according to the age.

\begin{tabular}{|llllll|}
\hline \multicolumn{4}{|l|}{ Age group (years) } \\
\hline \multicolumn{17}{|l|}{$\mathbf{2 1 - 2 3}$} & \multicolumn{2}{l|}{$\mathbf{2 4 - 2 5}$} \\
\hline $\mathrm{N}$ & $(\%)$ & $\mathrm{N}$ & $(\%)$ & $\mathrm{N}$ & $(\%)$ \\
\hline $\mathbf{7 7}$ & 25.66 & 160 & 53.33 & 63 & 21.00 \\
\hline Mean \pm SD & & $21.98 \pm 2.002$ & & \\
\hline
\end{tabular}

The cases under study were classified into different socioeconomic categories according to modified Kuppuswamy's scale. The maximum number of cases was found in the lower middle class socioeconomic status i.e. 155 cases $(51.7 \%)$ and 145 cases $(48.3 \%)$ from upper middle class socioeconomic status. No cases of upper and lower socioeconomic status were present. 255 cases $(85 \%)$ had regular cycles with a cycle length of 21 to 35 days. While only 45 cases $(15 \%)$ had irregular cycles (Table 2).

Table 2: Distribution of menstrual cycle pattern among cases under study.

\begin{tabular}{|c|c|c|}
\hline Menstrual cycle & $\mathbf{N}$ & $\%$ \\
\hline Irregular & 45 & 15 \\
\hline Regular & 255 & 85 \\
\hline Total & 300 & 100 \\
\hline
\end{tabular}

Table 3: Distribution of cases according to menstrual cycle length.

\begin{tabular}{|lll|}
\hline Type of menstrual pattern & N & $\%$ \\
\hline Irregular (no fixed length) & 10 & 3.3 \\
\hline Polymenorrhea/short cycles & 9 & 3.0 \\
\hline Oligo/prolonged cycles & 26 & 8.7 \\
\hline Normal cycle & 255 & 85 \\
\hline Total irregular cycle & 45 & 15 \\
\hline Total & 300 & 100 \\
\hline
\end{tabular}

There were 255 cases $(85 \%)$ with normal cycle of 21 to 35 days length. Long cycles (oligomenorrhea) was found to be present in 26 cases $(8.7 \%)$. Long cycles were taken as cycle length above 35 days. Cases with short cycles (polymenorrhea) i.e. cycle length less than 21 days were
$9(3.0 \%)$ in number. 10 cases $(3.3 \%)$ had no fixed cycle length and their cycle was not predictable (Table 3 ).

Maximum number of cases i.e. 121 cases $(40.3 \%)$ used 3 pads per day. 118 cases $(39.3 \%)$ used only 2 pads per day. Only 8 cases $(2.7 \%)$ had scanty blood flow during menses and required only one pad daily. 5 cases $(1.7 \%)$ used 5 pads daily while 2 cases $(0.7 \%)$ had to use 6 or more pads per day. Four or more than 4 pads used per day was labelled as menorrhagia, while 1 pad per day was said to be hypomenorrhoeic. Total of 53 cases $(17.66 \%)$ were having menorrhagia and only 8 cases $(2.7 \%)$ were having hypomenorrhoea. There were 214 cases $(71.33 \%)$ with average days of menstrual flow of 4-6 days. 76 cases $(25.33 \%)$ cases were present that had 2-3 days of menstrual flow. Only 10 cases $(3.33 \%)$ had an average 7-8 days of flow.

Table 4: Distribution according to presence of dysmenorrhoea.

\begin{tabular}{|lll|}
\hline Dysmenorrhoea & $\mathbf{N}$ & $\%$ \\
\hline No & 72 & 24.0 \\
\hline Yes & 228 & 76.0 \\
\hline Total & 300 & 100.0 \\
\hline
\end{tabular}

Table 5: Distribution of cases according to presence of abdominal crampsduring menses.

\begin{tabular}{|lll|}
\hline Abdominal cramps & N & $\%$ \\
\hline No & 98 & 32.7 \\
\hline Yes & 202 & 67.3 \\
\hline Total & 300 & 100.0 \\
\hline
\end{tabular}

Table 6: Distribution of cases according to other premenstrual symptoms.

\begin{tabular}{|lccccc|}
\hline Symptoms & $\begin{array}{l}\text { Yes } \\
(\mathbf{N})\end{array}$ & $\%$ & $\begin{array}{l}\text { No } \\
(\mathbf{N})\end{array}$ & $\%$ & Total \\
\hline Fatigue & 163 & 54.3 & 137 & 45.7 & 300 \\
\hline Leg cramps & 159 & 53.0 & 141 & 47 & 300 \\
\hline $\begin{array}{l}\text { Bladder and } \\
\text { bowel problems }\end{array}$ & 48 & 16.0 & 252 & 84.0 & 300 \\
\hline Headache & 47 & 15.7 & 253 & 84.3 & 300 \\
\hline $\begin{array}{l}\text { Nonspecific } \\
\text { mastalgia }\end{array}$ & 41 & 13.7 & 259 & 86.3 & 300 \\
\hline Giddiness & 37 & 12.3 & 263 & 87.7 & 300 \\
\hline Depression & 36 & 12.0 & 264 & 88.0 & 300 \\
\hline $\begin{array}{l}\text { Nausea and } \\
\text { vomiting }\end{array}$ & 26 & 8.7 & 274 & 91.3 & 300 \\
\hline $\begin{array}{l}\text { Bloating/ } \\
\text { swelling }\end{array}$ & 24 & 8.0 & 276 & 92.0 & 300 \\
\hline Gritty breast & 12 & 4.0 & 288 & 96 & 300 \\
\hline
\end{tabular}

Out of total 300 cases 105 cases $(35 \%)$ had the history of passage of clots and 195 cases $(65 \%)$ did not give history of passage of clots. Passage of clots during menses is suggestive of excessive amount of bleeding as normally 
the menstrual blood does not clot due to anticoagulant content of vaginal secretions. In the present study dysmenorrhoea was present in 228 cases i.e. $76 \%$ while 72 cases i.e. $24 \%$ had no such complaint. Absence of dysmenorrhoea is highly suggestive of anovulatory cycles as most of the ovulatory cycles are painful due to release of prostaglandin (Table 4).

Out of the total 300 cases, 202 cases i.e. $67.3 \%$ had the complaint of abdominal cramps during menses and 98 cases i.e. $32.7 \%$ denied any cramps during their menses (Table 5).

Out of other premenstrual symptoms, fatigue was present in 163 cases i.e. $54.3 \%$ while 137 cases $(45.7 \%)$ had no such problem. 159 cases $(53 \%)$ had the complaint of leg cramps during menses and 141 cases $(47 \%)$ had no leg cramps. 48 cases $(16 \%)$ had bladder and bowel problems like constipation, loose motions, and increased frequency of micturition. 41 cases $(13.7 \%)$ cases had non specific mastalgia. 37 cases $(12.3 \%)$ complained of giddiness during menses. Depression was present in 36 cases i.e. $12 \%$. Nausea and vomiting was present in 26 cases $(8.7 \%)$. Bloating and swelling was present in 24 cases $(8.0 \%)$ (Table 6).

\section{DISCUSSION}

The mean age of study sample was found to be 21.98 years with a standard deviation of 2.0. There are maximum cases in 22 and 23 years of age i.e. 55 each. 40 cases belonged to 20 years and 25 years each. Minimum numbers of cases were present in the age 24 years. None of cases were present in 17 and 18 years. Maximum number of cases i.e.121 cases $(40.3 \%)$ used 3 pads per day. 118 cases $(39.3 \%)$ used only 2 pads per day. Only 8 cases $(2.7 \%)$ had scanty blood flow during menses and required only one pad daily and 5 cases $(1.7 \%)$ used 5 pads daily while 2 cases $(0.7 \%)$ had to use 6 or more pads per day. Considering menorrhagia when the number of pads used per day was more than 4 , total of 53 cases $(17.33 \%)$ were present. Similar results were obtained by Naveen samir et al who found $11.7 \%$ cases of menorrhagia in his study. The mean age of menarche in the present study was $13.50 \pm 1.315$ years, which was almost consistent with earlier reports from different geographical areas of India and different parts of the world. ${ }^{11}$ Singh et al found cases $(8.7 \%)$. Bloating and swelling was present in 24 cases $(8.0 \%)$. Hirsutism was present in only 4 cases $(1.3 \%)$. Acne was found to be less common and was present inonly 36 cases $(12 \%)$. Similar age of menarche $(12.5 \pm 1.52$ years $){ }^{12}$ Begum also got similar results, (12.6 \pm 1.0 years) Kavitha also reported age of menarche of 12.5 years..$^{9,13}$ Similar study conducted by Esimai in Nigeria also found age of menarche around 14.2 years. ${ }^{14}$ Study done by Rigon et al also got similar age of menarche $(12.4 \pm 1.3$ years $) .{ }^{15}$

In current study, 255 (85\%) of participants had regular cycles whereas 45 cases $(15 \%)$ had irregular cycles. Out of 45 cases with irregular cycle 10 cases (3.3\%) had no fixed cycle length, $9(3 \%)$ had short cycles i.e. cycle length less than 21 days, $26(8.7 \%)$ had long cycles i.e. cycle length more than 35 days. A study conducted among the girl students in Ratnagiri, Maharashtra, India, by Patil in 2009 also, reported $83.1 \%$ girls with regular and $16.9 \%$ with irregular cycles. ${ }^{16}$ Study conducted in Nigeria by Umeora also found that $63.5 \%$ respondents had regular and $36.5 \%$ had irregular menstrual cycles. ${ }^{17}$ Mohite et al also reported $73.8 \%$ subjects with regular and $26.1 \%$ had irregular cycle among the college students. ${ }^{18}$ The minor difference among the various studies was mainly due to environmental, racial, nutritional and lifestyle factors.

There were 214 cases $(71.33 \%)$ with average days of menstrual flow of 4-6 days. 76 cases $(25.33 \%)$ cases were present who had 2-3 days of menstrual flow. Only 10 cases $(3.33 \%)$ had an average 7-8 days of flow. Dysmenorrhoea and premenstrual symptoms are common disorders that affect more than $50 \%$ of the menstruating women. ${ }^{19}$ The proposed cause of pain in dysmenorrhoea is excess production of prostaglandins (PG) in the endometrium during the ovulatory cycle. It was shown that women with dysmenorrhoea have higher levels of PG in their plasma and menstrual discharge than women without dysmenorrhoea. ${ }^{20}$ Pre-menstrual symptoms are experienced prior to menstruation dueto changes in blood levels of estrogen as well as progesterone. ${ }^{21}$ In the present study, dysmenorrhoea and premenstrual symptoms were experienced by significant number of students with normal body weight (50\%). Dysmenorrhoea had no significant associationwith menstrual cycle pattern. The $\mathrm{p}$ value obtained was 0.289 . It means that dysmenorrhoea is present in both the cases i.e. either with regular cycles or with irregular cycles. Similar results were obtained by a study conducted by Lakkawar on medical students in Pondicherry. ${ }^{22}$ Out of other premenstrual symptoms, fatigue was found to be more common and was present in 163 cases $(54.3 \%)$ while 137 cases $(45.7 \%)$ had no such problem. 159 cases $(53 \%)$ had the complaint of leg cramps during menses and 141 cases $(47 \%)$ had no leg cramps. 48 cases $(16 \%)$ had bladder and bowel problems like constipation, loose motions, and increased frequency of micturition. 41 cases $(13.7 \%)$ cases had non specific mastalgia. 37 cases (12.3\%) complained of giddiness during menses.

\section{CONCLUSION}

The mean age of menarche was found to be 13.50 years with standard deviationof 1.315 . The average duration of normal blood flow for reproductive age group as estimated is 2-5 days. The mean of menstrual cycle length came out to be 29.79 days with a standard deviation of 4.87 . The average amount of blood loss during each menstrual cycle was found to be $65.39 \mathrm{ml}$ with a standard deviation of 11.81 . 


\section{ACKNOWLEDGMENTS}

Authors would like to thank all patients for extending their kind co-operation during current study.

Funding: No funding sources

Conflict of interest: None declared

Ethical approval: The study was approved by the Institutional Ethics Committee

\section{REFERENCES}

1. McPherson M, Korfine L. Menstruation across time: menarche, menstrual attitudes, experiences, and behaviors. Women Health Issues. 2004;(14):193200.

2. Venturoli S, Porcu E, Fabbri R. Longitudinal evaluation of the different gonadotropic pulsatile patterns in anovulatory cycles of young girls. J Clin Endocrinol Metab. 1992;74(4):836-41.

3. Flug D, Largo RH, Prader A. Menstrual patterns in adolescent Swiss girls: A Longitudinal study. Ann Hum Biol. 1984;11(6):495-508.

4. Critchley H, Lumsden M, Campbell-Brown M, Douglas A, and Murray G. Menorrhagia I: measured blood loss, clinical features, and outcome in women with heavy periods: a survey with follow-up data. Am J Obstet Gynecol. 2004;190:1216-23.

5. Hickey M, Balen A. Menstrual disorders in adolescence: investigation and management. Hum Reprod Update. 2003;9:493-504.

6. Fujiwara T. The discrepancy between BMI and selfrecognition of adequate body weight may cause insufficient food intake and habits in young women in Japan. Bull Ashiya Col. 2005;27:75-80.

7. Alam T, Jiwane R, Choudhary AK, Kishanrao SS. Relationship of body mass index \& the age at menarche among young girls. J Dent Med Sci. 2015; 14:79-83.

8. Widholm O, Kantero RL. A statistical analysis of the menstrual patterns of 8,000 Finnish girls and their mothers. Acta Obstet Gynecol Scand Suppl. 1971; 14:1-36.

9. Begum J, Hossain AM, Nazneen SA. Menstrual pattern and common menstrual disorders among students in Dinajpur. Med Col. 2009;2:37-43.

10. Malhotra N, Kumar P, Malhotra J, Bora MN, Mittal P. Jeffcoat ${ }^{\text {ee }}$ s principles of gynaecology. 8th ed. New
Delhi: Jaypee Brothers: 2014;80-1.

11. Nevin S, Fattah HA, Sayed EM. The correlation between body mass index and menstrual profile among nursing students of Ain Shams University. Egypt Nurs J. 2011;5 (8):52-9.

12. Singh A, Kiran D, Singh H, Nel B, Singh P, Tiwari P. Prevalence and severity of dysmenorrohea: A problem related to menstruation among first and second year female medical students. Indian J Physiol Pharmacol. 2008;52(4):389-97.

13. Kavitha C, Jamuna BL. A study of menstrual distress questionnaire in first yearmedical students. Int J Biol Med Res. 2013:4(2):3192-5.

14. Esimai OA, Omoniyi EGO. Awareness of menstrual abnormality amongst college students in urban area of Ile-Ife, Osun State, Nigeria. Ind J Comm Med. 2010;35(1):63-6.

15. Rigon F, De Sanctis V, Bernasconi S, Bianchin L, Bona $\mathrm{G}$, Bozzola $\mathrm{M}$, et al. Menstrual pattern and menstrual disorders among adolescents: an update of the Italian data. Ital J Pediatrics. 2012:38:38-46.

16. Patil SN. Health profile amongst adolescent girls in rural area of Ratnagiri district of Maharashtra. India J Clin Diag Res. 2009;5:1784-90.

17. Umeora O, Egwuatu V. Age at menarche and the menstrual patterns of Igbo women of Nigeria. African J Reprod Health. 2008;12(1):90-95.

18. Mohite RV, Mohite VR. Correlates of the menstrual problems among rural college students of Satara district. Al Ameen J Med Sci. 2013;6(3):213-8.

19. The ACOG American college of obstetrician and gynaecologists. Dysmenorrhoea. Tech Bull ACOG. 1983;63:2-5.

20. Sun MF, Huang HC, Lin SC, Chang LP, Liu CF. Evaluation of nitric oxide and homocysteine levels in primary dysmenorrhoeal women in Taiwan. Life Sci. 2005;76(17):2005-9.

21. Dangal G. Menstrual disorders in adolescents. Int $\mathbf{J}$ Gynaec Obst. 2004;4(1):52-9.

22. Lakkawar NJ, Jayavani RL, Nivedhana AP, Padma A, Vanajakshi NA. Study of menstrual disorders in medical students and its correlation with biological variables scholars. J App Med Sci. 2014;2(6):316-9.

Cite this article as: Jaiswal D, Kumar R. Magnitude of menstrual problems among young females of medical and paramedical college. Int J Reprod Contracept Obstet Gynecol 2021;10:2010-4. 